\title{
Employees' Attitude Towards E-HRM Practices At Maruti Suzuki India Limited (MSIL), India
}

\author{
Dr. Manisha Vijayran \\ Assistant professor, Shahba College of Business Administration, \\ Faculty of Administrative and Financial Sciences, Al-Baha University, \\ P-O-Box-1988, Al-Baha-65431,Kingdom Of Saudi Arabia \\ E-mail - vijayran.m@gmail.com
}

\section{ABSTRACT}

Organizations these days are motivated to use digital processes in almost all their activities and departments. This paper describes E-HRM as an innovative trend that has picked up the buzz off late. E-HRM is a new term used for IT supported HRM in which organizations use web-based technologies for improving HR operational processes, human resource planning, acquiring, developing and retaining. It also allows employees to have a direct access to their information online and helps in providing better decision support. The present research paper measured the attitude of employees towards this HR technology in detail. A sample of 100 employees from MSIL, based in India has been taken for the present study so as to know their attitude towards e-HRM practices. Statistical tool Chi- Square test has been used for analyzing the data. The results of the study by and large show that employees have positive attitude towards e-HRM practices that result in cost reduction and reduction of the administrative burden.

Key Words: e-HRM, HRM digitization, decision support, attitude measurement.

\section{Introduction}

The human resource practices in organizations are maturing to meet the pace of the digitizing business environment. E-HRM is used interchangeably with virtual HRM, HR intranet, webbased HR, computer-based human resource management systems (CHRIS), and HR portals (Ruel et al., 2004).

"an umbrella term covering all possible integration mechanisms and contents between HRM and Information Technologies, aiming at creating value within and across organizations for targeted employees and management"

"an umbrella term covering all possible integration mechanisms and contents

between HRM and Information Technologies, aiming at creating value within and across organizations for targeted employees and management"

"an umbrella term covering all possible integration mechanisms and contents

between HRM and Information Technologies, aiming at creating value within and across organizations for targeted employees and management"

Bondarouk and Ruel (2009) defined E-HRM as "An umbrella term covering all possible integration mechanisms and contents between HRM and information technologies aiming at creating value within and across organizations for targeted employees and management"

E- HRM is defined as the administrative support of the HR function in organizations by using internet technology (Voermans and Veldhoven, 2007).

E- HRM is also defined as a way of implementing HR strategies, policies and practices in organizations through a conscious and directed support of, and or with the full use of, web- 
technology- based channels (Bondarouk and Velde, 2007). On one hand E-HRM focuses on making the HR processes faster, user friendly and accurate so that the efficiency of the organizational processes improves. On the other hand the introduction of E-HRM is expected to facilitate a more efficient and strategic way of working for HR professionals (Gardner et al., 2003; Shrivastava and Shaw, 2003).

In this paper attempt have been made not only to study the technology aspect of E- HRM but also the change in the positioning and perspective of HR function which runs parallel to its implementation and the acceptance by the employees. There are certain important factors that have been kept in mind while writing this paper which significantly affect the implementation of E- HRM. These factors are employees' understanding of E- HRM, employees' ability to cope with major changes in his dealing with the HR personnel and the support he would get while he is accessing the newly incorporated E- HR systems. Reception and assimilation by employees is considered to be an important factor when implementing EHRM.

The literature on E- HRM suggests that, overall the three goals of E- HRM are cost reduction, improving HR services, and improving strategic orientation (Brockbank, 1997; Lepak and Snell, 1998; Ruel et al. 2004 ; Stanton and Covert, 2004). Panayotopoulou et al. (2007) in their research had identified array of reasons for e-HRM adoption in an organisation which includes operating cost reduction (Stanton and Coovert, 2004) company image enhancement and time management etc. They concluded that collaboration between human resource (HR) and IT can be considered as the most success factors for e-HRM adoption.

The ability to cope with changes in the HR function and the support that is provided to employees during E- HRM implementation is also deemed essential (Haines and Pettit, 1997; Fisher and Howell, 2004; Ruta, 2004). However, there are not many studies done on employees' attitude towards E- HRM practices and their implementation in an organization. According to some other studies there are many other variables that have an effect on the attitude towards IT systems. As these variables affect the attitude towards other IT systems they may also have an effect on E- HRM as well. These variables are: length of service in a company and level of job experience (Gardner et al., 2003), age (Igbaria and Nachman, 1990; Haines and Petit, 1997), gender (Yuen and Ma, 2002; Venkatesh et al., 2003) and General IT knowledge (Orlikowski, 2000; Igbaria and Chakrabarti, 1990b; Ray et al., 1999). In the present study soe of these variables have been taken (details are mentioned in the research methodology).

This paper explains the employees' attitude towards E- HRM systems and measures it by using suitable research technique namely chi-square. The starting point of our research is based on the technology acceptance model (TAM). This model helps in understanding the acceptance of technology by the employees and their general attitude towards IT systems. Later on, ERP Module, OASIS portal and HRIS of MSIL are discussed .Finally, to ascertain the attitude of employees towards e-HRM systems, various factors like allocation of adequate funds for designing and usage of e-HRM programs by the management, involvement of supervisors and employees by the managers to plan e-HRM programs, training to employees for usage of e-HRM programs, effective e-HRM Wizards/ messages to help in filling forms, e-HRM fulfills the need for increased flexibility, productivity and efficiency, e-HRM lowers costs and saves time and e-HRM as a symbol of higher status have been studied. 


\section{Technology Acceptance Model}

The Technology Acceptance Model (TAM) is one of the most influential extensions of the theory of reasoned action (TRA) given by Ajzen and Fishbein (Ajzen, I., \& Fishbein, M. 1980). TAM was developed by Fred Davis and Richard Bagozzi (Bagozzi et al., 1992; Davis et al., 1989). TAM discusses two technology acceptance measures - ease of use, and usefulness. This model has been widely accepted by researchers to study the human aspects of technological innovations. The attitude of individuals that is highly influential in the acceptance of new technology is described by the central relationship in this model. The likelihood of future system use by individuals is considered as central and it is described by the experienced ease of use and experienced usability. The purpose of the model is to achieve better insight in processes and outcomes of information technology (IT) implementations (Davis, 1989). Although the TAM model has been criticized over the years and slight adjustments have been suggested (Legriset al., 2003), the crux is still accepted as highly relevant.

The TAM model explains two factors, which help in forming the basis for attitude formation towards IT. The model suggests that when users are presented with a new technology, a number of factors influence their decision about how and when they will use it. One of them is perceived usefulness- This was defined by Fred Davis as "the degree to which a person believes that using a particular system would enhance his or her job performance". The other one is perceived ease-of-use - it was defined as "the degree to which a person believes that using a particular system would be free from effort" (Davis, 1989).

The attitude formation here further encourages the person to develop an intention to use IT which leads to actual use. Figure 1 shows this technology acceptance model.

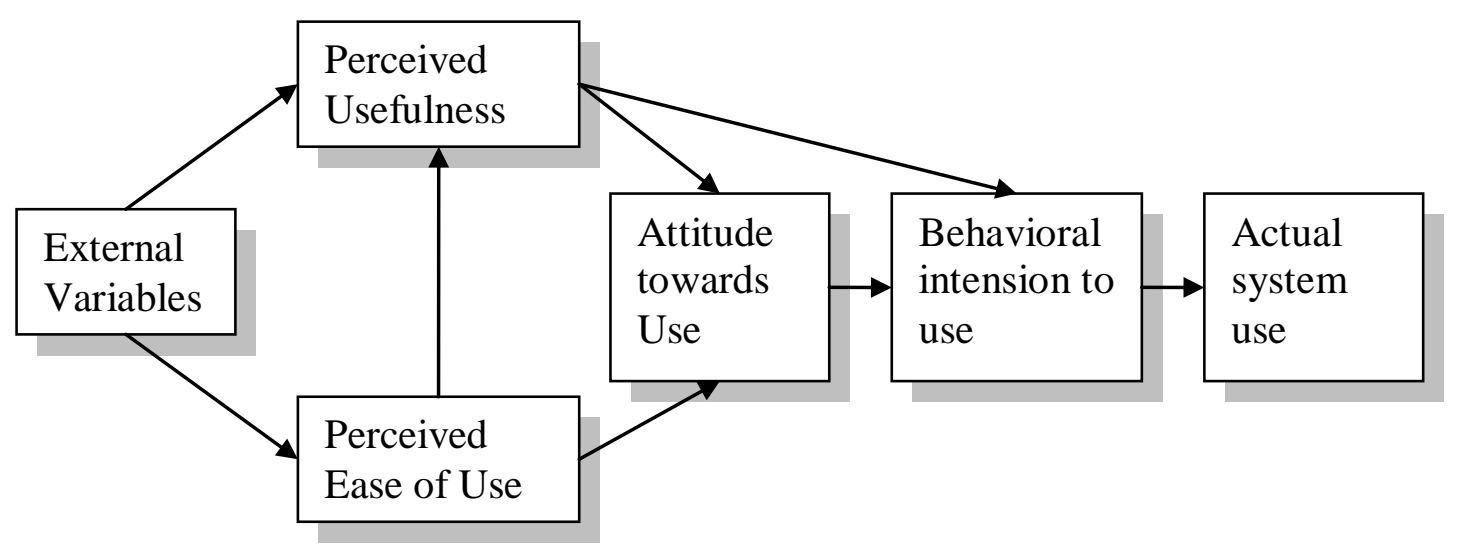

Figure 1: Technology Acceptance Model

Source: Davis, F.D. (1989), "Perceived usefulness, perceived ease of use, and user acceptance of information technologies”, MIS Quarterly, Vol. 13 No. 3, pp. 319-40.

In this paper these two factors have been studied as employees seem to develop a general attitude towards IT based systems because of their IT experiences and their usage. When researching the ease of use, a distinction is often made between ease of use of the application/technology itself and support provided by the organization for users. Also, when researching the usability, a distinction is often made between the usability of the application/technology itself and the overall quality of the output/service delivered by the application/technology (Davis, 1993). 


\section{ERP}

A new generation network system, Enterprise Resource Planning, or ERP, has been added to the IT infrastructure at Maruti. This online processing system has brought all business processes within a single network, thereby creating greater synergy among them. Another significant aspect of ERP is that it has enabled enhanced interaction between employees within the company - they can service themselves online for many needs. The ERP system has a wide application. Right from finance processes, such as processing of bills and payments, to human resource management, to production and sales, to procurement of goods \& services from suppliers in the large supply chain network, ERP integrates all these functions to a common IT network. For the ERP network, Maruti collaborated with Oracle India Pvt. Ltd., the India division of the world's largest enterprise software company. The most important outcome of ERP is the standardization of processes across various business units. This eliminates scope for application of different methods for a particular task.

\section{OASIS Portal at MSIL}

Oasis, the employee portal has been developed for easy access across the extended organization. The scope of the portal is to provide effective information delivery, and streamline application services within the organization. Oasis has been designed to address the challenge of collaboration - so that you can connect to the right person, at the right time to gain access to the right resources.

- Currently stands as an Information Portal with over 6,000 pages

- Focuses on dissemination of knowledge through well researched features/analyses

- Acts as a Resource Centre for the organization

- Is widely used for business updates and global trends, as well as, educational, general awareness and recreational needs

The act of sharing knowledge, embodied in OASIS must help all employees do a better job, whatever their function.

\section{HUMAN RESOURCE INFORMATION SYSTEM (HRIS)}

Human Resource is another widely implemented ERP module. ERP HR module streamlines the management of human resources and human capitals. HR modules routinely maintain a complete employee database including contact information, salary details, attendance, performance evaluation and promotion of all employees. Advanced HR module is integrated with knowledge management systems to optimally utilize the expertise of all employees.

ERP HR modules, refers to the systems and processes at the intersection between human resource management (HRM) and information technology. On the whole, these ERP systems have their origin on software that integrates information from different applications into one universal database. The linkage of its financial and human resource modules through one database is the most important distinction to the individually and proprietary developed predecessors, which makes this software application both rigid and flexible.

The HR management module is a component covering many other HR aspects from application to retirement. The system records basic demographic and address data, selection, training and development, capabilities and skills management, compensation planning records and other related activities. Leading edge systems provide the ability to "read" applications and enter relevant data to applicable database fields, notify employers and provide position management and position control. Human resource management function involves the recruitment, placement, evaluation, compensation and development of the employees of an organization. 


\section{Purpose of HRIS}

The function of Human Resources departments is generally administrative and common to all organizations. Organizations may have formalized selection, evaluation, and payroll processes. Efficient and effective management of "Human Capital" has progressed to an increasingly imperative and complex process. The HR function consists of tracking existing employee data which traditionally includes personal histories, skills, capabilities, accomplishments and salary. To reduce the manual workload of these administrative activities, organizations began to electronically automate many of these processes by introducing specialized Human Resource Management Systems. Due HR executives rely on internal or external IT professionals to develop and maintain an integrated HRMS. Before the "client-server" architecture evolved in the late 1980s, many HR automation processes were relegated to mainframe computers that could handle large amounts of data transactions. In consequence of the high capital investment necessary to purchase or program proprietary software, these internally-developed HRMS were limited to organizations that possessed a large amount of capital. The advent of client-server, Application Service Provider, and Software as a Service or SaaS Human Resource Management Systems enabled take increasingly higher administrative control of such systems. Currently Human Resource Management Systems encompass:

1. Payroll

2. Work Time

3. Benefits Administration

4. HR management Information system

5. Recruiting

6. Training/ Learning Management System

7. Performance Record

HRIS enables employees to see their pay, accrued benefits and basic information via the web and update some portions of it (name, and address for example),processes information at high speed, act as a decision support tool and strengthens the control of the management and provides accurate information.

\section{Research Methodology}

The respondents are from the manufacturing unit of Maruti Suzuki India Limited (MSIL, formerly Maruti Udyog Limited) situated in Gurgaon, Haryana. It is a subsidiary of Suzuki Motor Corporation of Japan and is India's largest passenger car company, accounting for over 50 per cent ( 55\% approx.) of the domestic car market. A sample of 100 respondents were selected randomly from various departments for the present study. The company has already implemented ERP processes to be in sync with the changing technological trends. E- HRM systems are one of these digital systems that the company has incorporated in order to make its HR processes more sophisticated, user friendly and efficient. This research has been conducted using a specially designed questionnaire from 100 employees. The questionnaire 14 questions apart from control variables which were measured on a 5 point Likert Scale (1Strongly Disagree to 5- Strongly Agree). Chi square test was used to determine the association between the study variables and attitude of employees towards E- HRM practices undertaken at MSIL.

\section{Results}

It was observed that employees with work experience of upto 10 years regarded the investment made by the management in designing E- HRM programs adequate as compared to employees with higher work experience. A highly positive attitude was observed amongst the employees under the age group of 30 years towards the management's initiative to spend 
money on digital processes. It was quite interesting to note that graduates showed better attitude towards E- HRM practices than post graduate employees. However, there was no significant relationship between the gender (male and female) and position with the E- HRM investments made by the organization.

Table 1:Allocation of Adequate Funds for Designing and Usage of E-HRM Programs by the Management

\begin{tabular}{|l|l|l|l|l|l|}
\hline \multicolumn{5}{|l|}{ CONTROL VARIABLES } \\
\hline & Gender & $\begin{array}{l}\text { Job } \\
\text { Experience }\end{array}$ & Position & Age Group & Qualification \\
\hline 1 & 1.48 & $5.71 *$ & 2.46 & $12.51 *$ & $5.97 *$ \\
\hline 2 & 0.20 & $6.76 *$ & $14.05 *$ & $13.30 *$ & 0.43 \\
\hline 3 & 0.10 & $9.64 *$ & $20.48 *$ & $11.61 *$ & 2.75 \\
\hline 4 & 1.89 & $13.65 *$ & 3.01 & $10.84 *$ & $7.88 *$ \\
\hline 5 & 0.38 & $10.88 *$ & $6.12 *$ & $6.61 *$ & 0.62 \\
\hline 6 & $4.45 *$ & $6.85 *$ & 3.01 & $6.74 *$ & $5.84 *$ \\
\hline 7 & 2.96 & 0.57 & 4.58 & $10.15 *$ & 2.20 \\
\hline $\begin{array}{l}\text { Degrees Of } \\
\text { Freedom }\end{array}$ & 1 & 1 & 2 & 2 & 1 \\
\hline
\end{tabular}

* Significant at $5 \%$

(Word count - 4344)

Involvement of supervisors and employees by the Managers to plan e-HRM programs It is always better to have 360 degree involvement of the people in an organization to develop new processes so that they feel that they are a part of the new developments made in the organization. From the analysis done above it was evident that employees with upto 10 years of experience are more satisfied with their involvement in planning E- HRM programs as compared to those with higher experience. Middle level employees showed highest satisfaction for their involvement for strategic planning opportunities given to them by their managers. Employees belonging to less than 30 years of age group showed highest positive attitude for their contribution in planning for the E-HRM programs.

\section{Training to employees for usage of e-HRM programs}

It is very important to impart training to employees for using digital/ electronic processes so that they do not make any mistakes while filing their particulars and details in them. The observation made for this factor was that the employees who had a work experience of upto 10 years were more satisfied with the training provided to them for proper usage of E-HRM programs. The employees in the middle management were also very positive towards the training given to them by their management. Younger employees had more interest in attending training programs as these were new to them and they had more inclination towards learning latest softwares for efficient processing of their data.

\section{Effective e-HRM Wizards/ messages to help in filling forms}

E-HRM systems must have standardized messages for each screen that the employee is filling so that there is no inconvenience in filling up data by the employees. This further helps in reducing the work of the HR professional sas they do not have to cater to the queries of each employee who faces a problem while filling/ updating information in the E- HRM system. The graduates who are below 30 years of age and have been working in this organization for upto 10 years showed a highly motivating attitude towards the ease with which they can fill up their information in the E- HRM systems because they find them very user friendly. All 
the screens show adequate messages and dialog boxes to increase the convenience of filling up the required forms.

\section{E-HRM fulfills the need for increased flexibility, productivity and efficiency}

The employees with experience of less than 10 years at middle level position find these digitized HRM processes very efficient. However employees with more than 10 years of work experience did not have the same viewpoint. According to the employees in the age category of less than 30 years portrayed a positive attitude towards this factor as flexibility of usage the software was of more importance to them.

\section{E-HRM lowers costs and saves time}

According to the observation made from the analysis the male employees are of the viewpoint that E-HRM softwares save a lot of their precious time and reduce unnecessary expenditure of the company on stationary and other office material required in HRM processes. They feel that paperless offices are more efficient to manage than piles of files lying in the cupboards. The female employees differ with them on this viewpoint. The employees with work experience of more than 10 years and who are post graduates also differ in their attitude towards the fact that E-HRM saves time and reduces cost. This maybe due to rigidity to change with the changing times as these people are so used to using traditional system of maintaining records and doing lot of paperwork.

\section{E-HRM as a symbol of higher status}

Employees in the age group of less than 30 years consider E-HRM as a symbol of higher status and believe that using E-HRM gives them and their organization an edge above others. All the other variables do not show significant values for this factor.

\section{Discussion and conclusion}

Overall Gender and qualification do not have a significant impact on the attitude of the employees towards E- HRM programs at MSIL. However, the youngest group of less than 30 years of age appeared to have most favorable and positive attitude towards digitization of HRM processes. Also, graduates at middle level positions were most satisfied with the usage, flexibility and productivity enhanced by E-HRM programs. It is evident that the electronic processes reduce cost and save time, therefore the senior management employees should be imparted adequate training on the importance of these factors so that they adapt to the changing environment and rapidly changing nature of knowledge.

\section{References}

1. Adams, D. A., Nelson, R. R., \& Todd, P. A.,(1992);Perceived usefulness, ease of use, and usage of information: A replication, MIS Quarterly, 16(2), 227-247.

2. Agarwal, R., \& Prasad, J.,(1999); Are individual differences germane to the acceptance of new information technologies? Decision Sciences, 30(2), 361-391.

3. Ajzen, I., \& Fishbein, M.,(1980);Understanding attitudes and predicting social behavior, Englewood Cliffs, NJ: Prentice-Hall.

4. Al-Gahtani, S.,(2001); The applicability of TAM outside North America: An empirical test in the United Kingdom, Information Resources Management Journal, 14(3), 37-46.

5. Bondarouk, T. and Ruel, H.J.M. (2009); Electronic Human Resource Management: Challenges in the digital era, The International Journal of Human Resource Management, Vol.20, pp.505-514.

6. Brosnan, M. J.,(1999); Modeling technophobia: A case for word processing, Computers in Human Behavior, 15(2), 105-121. 
7. Brockbank, W. (1997), "HR's future on the way to a presence", Human Resource Management, Vol. 36 No. 1, pp. 65-70.

8. Chau, P. Y. K., \& Hu, P. J.,(2002); Investigating healthcare professionals' decisions to accept telemedicine technology: An empirical test of competing theories, Information \& Management, 39(4), 297-311.

9. Davis, F.D., (1989); "Perceived usefulness, perceived ease of use, and user acceptance of information technologies”, MIS Quarterly, Vol. 13 No. 3, pp. 319-40.

10. Dishaw, M. T., \& Strong, D. M.,(1999); Extending the technology acceptance model with task-technology fit constructs, Information \& Management, 36(1), 9-21.

11. Gardner, S.D., Lepak, D. and Bartol, K.M.,(2003); Virtual HR: the impact of information technology on the human resource professional, Journal of Vocational Behaviour, Vol. 63, pp. 159-79

12. Gefen, D., \& Straub, D. W.,(2000); The relative importance of perceived ease of use in IS adoption: A study of E-commerce adoption, Journal of the Association for Information Systems, 1(8), 1-28.

13. Gong, M., Xu, Y., \& Yu, Y.,(2004); An enhanced technology acceptance model for webbased learning, Journal of Information Systems Education, 15(4), 365-374.

14. Igbaria, M., Zinatelli, N., Cragg, P., \& Cavaye, A. L. M.,(1997);Personal computing acceptance factors in small firms: A structural equation model, MIS Quarterly, 21(3), 279-305.

15. Klopping, I. M., \& McKinney, E.,(2004);Extending the technology acceptance model and the task-technology fit model to consumer E-commerce, Information Technology, Learning and Performance Journal, 22(1), 35-48.

16. Koufaris, M.,(2002); Applying the technology acceptance model and flow theory to online consumer behavior, Information Systems Research, 13(2), 205-223.

17. Lepak, D.P. and Snell, S.A.,(1998);Virtual HR: strategic human resource management in the $21^{\text {st }}$ century, Human Resource Management Review, Vol. 8 No. 3, pp. 215-34.

18. Mathieson, K., (1991); Predicting user intentions: Comparing the technology acceptance model with the theory of planned behavior, Information Systems Research, 2(3), 173-191.

19. McCloskey, D.,(2003); Evaluating electronic commerce acceptance with the technology acceptance model, The Journal of Computer Information Systems, 44(2), 49-57.

20. Panayotopoulou, L., M. Vakola, and E. Galanaki (2007); eHR adoption and the role of HRM: evidence from Greece, Personnel Review, Vol. 36 No. 2, pp. 277294.

21. Riemenschneider, C. K., \& Hardgrave, B. C., (2001); Explaining software development tool use with the technology acceptance model, The Journal of Computer Information Systems, 41(4), 1-8.

22. Riemenschneider, C. K., Harrison, D. A., \& Mykytn, P. P.,Jr.,(2003); Understanding IT adoption decisions in small business: Integrating current theories, Information \& Management, 40(4), 269-285.

23. Ruta, C.D. (2005), "The application of change management theory to the HR portal implementation in subsidiaries of multinational corporations", Human Resource Management, Vol. 35, p. 53.

24. Roberts, P., \& Henderson, R.,(2000); Information technology acceptance in a sample of government employees: A test of the technology acceptance model, Interacting with Computers, 12(5), 427-443.

25. Ruel, H., Bondarouk, T. and Looise, J.,(2004); E-HRM: Innovation or Irritation? An Exploration of Web-based Human Resource Management in Large Companies, Lemma, Utrecht. 
26. Ruel Huub J.M. , Bondarouk Tanya V. and Velde Mandy Van der ,(2007); The contribution of e-HRM to HRM effectiveness, Employee Relations, Vol. 29 No. 3, pp. 280-291

27. Ruel H, Bondarouk T, Looise JK (2004). E-HRM: innovation or irritation: an explorative empirical study in five large companies on web based HRM. Manage. Rev., 15(3): 364 380.

28. Shrivastava, S. and Shaw, J. (2004), "Liberating HR through technology", Human Resource Management, Vol. 42 No. 3, pp. 201-22.

29. Spacey, R., Goulding, A., \& Murray, I.,(2004);Exploring the attitudes of public library staff to the internet using the TAM, Journal of Documentation, 60(5), 550-564.

30. Stanton, J.M. and M.D. Coovert (2004); Turbulent waters: the intersection of information technology and human resources, Human Resource Management, Vol. 43 No. 2, pp. 1216.

31. Shrivastava, S. and Shaw, J.,(2004); Liberating HR through technology, Human Resource Management, Vol. 42 No. 3, pp. 201-22

32. Stanton, J.M. and Coovert, M.D.,(2004); Turbulent waters: the intersection of information technology and human resources, Human Resource Management, Vol. 43 Nos 2/3, pp. 121-5.

33. Venkatesh, V., \& Davis, F. D., (1996); A model of the antecedents of perceived ease of use: Development and test, Decision Sciences, 27(3), 451-481.

34. Venkatesh, V.,(2000);Determinants of perceived ease of use: Integrating control, intrinsic motivation, and emotion into the technology acceptance model, Information Systems Research, 11(4), 342-365.

35. Vijayasarathy, L. R.,(2004); Predicting consumer intentions to use on-line shopping: The case for an augmented technology acceptance model, Information \& Management, 41(6), 747-762.

36. Voermans M. and Veldhoven M. Van,(2007) ; Attitude towards E-HRM: An Empirical Study at Philips, Personnel Review, Vol. 36 No. 6, pp. 887-902

37. Wang, W., \& Benbasat, I.,(2005); Trust in and Adoption of Online Recommendation Agents, Journal of the Association for Information Systems, 6(3), 72-101.

38. Wang, C., Hsu, Y., \& Fang, W.,(2004); Acceptance of technology with network externalities: An empirical study of internet instant messaging services. JITTA, Journal of Information Technology Theory and Application, 6(4), 15-28.

39. Wixom, B. H., \& Todd, P. A., (2005); A theoretical integration of user satisfaction and technology acceptance, Information Systems Research, 16(1), 85-102.

40. Yu, J. L. C., Liu, C., \& Yao, J. E., (2003); Technology acceptance model for wireless internet, Internet Research, 13(3), 206-222.

\section{Websites:}

http://www.scribd.com/doc/16405338/A-STUDY-ON-EMPLOYEES-ATTITUDETOWARDS-THE-ORGANISATION-WITH-SPECIAL-REFERENCE-TO-SAKTHISUGARS-LTD-SAKTHI-NAGAR 